\title{
A Framework to succeed IT Project Management in an era of Digital Transformation
}

\author{
Rachida HASSANI ${ }^{1}$, Younès EL BOUZEKRI EL IDRISSI ${ }^{2}$ \\ ${ }^{1}$ National School of Applied Sciences of Kenitra, Morocco, rachida.hassani22@gmail.com \\ ${ }^{2}$ National School of Applied Sciences of Kenitra, Morocco, y.elbouzekri@ gmail.com
}

\begin{abstract}
This article makes a general study of IT project management problems, specifically in an era of digital transformation. The collection of quantitative and qualitative data has been done by means of investigation reports already published in international groups, direct observation in the field (the case of an IT company), and interviews with project managers and different stakeholders during the implementation of IT projects. The results of this study allowed us to identify the key factors of failure of IT projects, which are directly related to the way this specific type of project is managed.

Throughout the observation, solutions to each problem were identified, tested, and improved. In order to propose a well-defined framework, for the management of IT projects. This framework is presented in the form of a project lifecycle, defining the different stages of each phase of the IT project lifecycle.
\end{abstract}

Key words : IT project, IT project management, Digital Transformation, IT project lifecycle.

\section{INTRODUCTION}

The human being evolves and his needs are constantly increasing exponentially and in light of speed, especially in an era of digital transformation, where companies are running behind the implementation of digital and IT tools, in order to meet their strategic needs that allow them to evolve. That said, there is more demand compared to the old times, when the computerization of business processes was a prestige to distinguish oneself from competitors.

The management of IT projects has been the concern of several generations, and remains a source of discomfort for companies who wish to make IT tools available to their end users for various reasons. There are many project management methods on the market, several definitions of the IT project lifecycle are available to project managers to meet their day-to-day constraints, but the figures are still very shocking, and trillions of euros are lost every year due to unsuccessful IT projects.
According to the Standish Group International report of 2003 , only $34 \%$ of IT projects are considered successful, while $66 \%$ of projects are considered challenged or failed because they exceed the initial budget, or the duration of their implementation, or are of poor quality. However, despite the development and implementation of IT project management processes, the figures remain catastrophic. Indeed, according to the report of the same group in 2013,39\% of projects are successful, while $61 \%$ are challenged or failed. It took 10 years to have a very slight improvement in IT project management [1].

The year 2013, coincides with the beginning of a new era, known as an era of digital transformation, which has its own constraints that directly impact the management of IT projects. A few years after the beginning of this era, we notice that the failure rate of IT projects has evolved [2]. Indeed, according to the Standish Group International report in 2015, only $29 \%$ of projects are successful, which makes $71 \%$ of projects failed or challenged. These figures are becoming more catastrophic, and very worrying for the future of this digital era [3].

There are several project management methods on the market, each with a well-defined life cycle. Beyond the management's methods, several tools and best practices, we find in the books. But, these present a macro plan for managing IT projects. However, once we go into the detail of each stage of the project life cycle, we find simple definitions, with too much risk of ambiguity and no details are put in place for the possible choices within those stages, and the steps and objectives of each phase of the life cycle.

The objective of this article is to identify the key factors of failure of IT projects, analyse, and propose solutions for each type of problem.

Could we identify the impact of the digital transformation of IT project management? Could we define a framework to define the different stages of each phase of the life cycle of an IT project? Could we circumvent the key factors of failure of an IT project by means of this framework? 


\section{LITERATURE REVIEW}

The PMI "Project Management Institute" defines a project as a temporary effort undertaken to create a product or service. It is characterized by a limited duration (a well-defined beginning and end), and is a means to implement the company's strategy [4].

IT projects are series of projects related to information technologies such as applications and websites, mobile applications, software, information systems or any other project resulting from computerization specifications [5]. Indeed, it is characterized by its uniqueness, urgency, one-shot, complexity, and risks [6].

According to these definitions, we could summarize that an IT project is a product or service, which has a strategic objective of the company and is part of the information technology field. This type of project, is characterized by a limited duration in time (a well-defined beginning and end), urgency, because they respond to a business strategy, uniqueness, because they are intended to meet a set of defined needs, complexity and a very high level of risk because they are part of an environment that changes very quickly over time.

IT project management refers to the practice of management that ensures the proper implementation of engineering systems development methods, which are based on management theory and science and are integrated into the practice of IT project development and a range of activities [7]. Indeed, according to $\mathrm{L}$. $\mathrm{Xu}$, the characteristics of IT project management can be translated by abstraction, timeliness of information communication and uncertainty [8]. While the PMI defines project management as the application of knowledge, skills, tools and techniques to project activities to meet project requirements [4].

These definitions allow us to conclude that IT project management, is the application of knowledge, skills, tools, techniques and management methods to project activities in order to meet a strategic business need through a product or service in the field of information technology.

In 1998, there was talk of an era of New Technologies of Communication and Information "NTIC". However, in 2013, fifteen years later, some of these technologies continue to be considered new, while others have emerged that have given rise to a new era, known as an era of digital transformation [9].

Digital transformation refers to the process that consists, for an organization, of fully integrating digital technologies into all of its activities. Indeed, this new business model, has become the main concern of all companies, in order to stay up to date and in line with the competition and follow the new expectations of users.

\section{METHODOLOGY}

\subsection{Theoretical background}

The management of IT projects has been always a subject of study and concern for the various project managers. Several methods have been developed in order to pursue the constraints of technological development, but the figures are still catastrophic, despite the various efforts made to ensure the success of this type of project.

According to the Chaos report published in 2016 by the Standish Group International (Table. 1) [10], we may well identify the rate of a slight improvement before 2013 and a return to deteriorate after that year. This year represents the beginning of the era of digital transformation, which in its role has called for new managerial constraints, specifically in the field of information technology.

Table 1: The Traditional resolution of all software projects from FY2011-2015 within the new CHAOS database.

\begin{tabular}{|c|c|c|c|c|c|}
\hline & $\mathbf{2 0 1 1}$ & $\mathbf{2 0 1 2}$ & $\mathbf{2 0 1 3}$ & $\mathbf{2 0 1 4}$ & $\mathbf{2 0 1 5}$ \\
\hline Successful & $39 \%$ & $23 \%$ & $41 \%$ & $36 \%$ & $36 \%$ \\
\hline Challenged & $39 \%$ & $46 \%$ & $40 \%$ & $47 \%$ & $45 \%$ \\
\hline Failed & $22 \%$ & $19 \%$ & $19 \%$ & $17 \%$ & $19 \%$ \\
\hline
\end{tabular}

Several factors have been identified during the different phases of the life cycle of an IT project, as a result of this study and the elements presented in the literature review.

\subsection{Hypotheses}

The hypotheses were developed to test the relationship between digital transformation and the failure rate of IT projects, as well as the methods and tools already in place for the conduct and management of IT projects. The surveys consist of the analysis of the different phases of the life cycle of an IT project implementation, regardless of the methods used.

Figure 1 summarizes the key phases analysed during the surveys: 


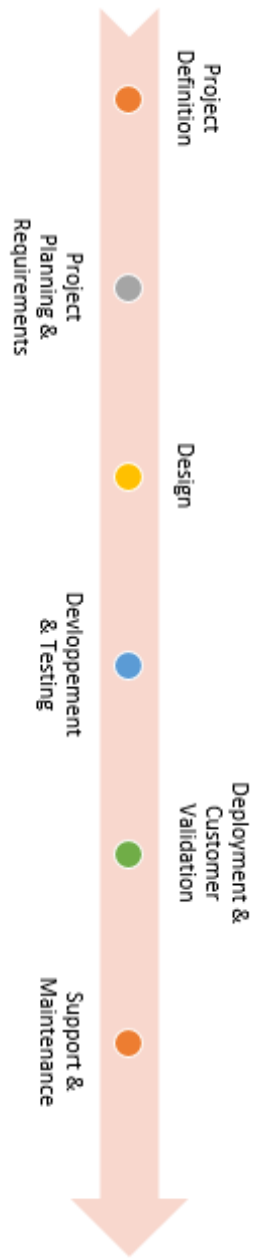

Figure 1: The main steps of an IT project lifecycle

\subsection{Population}

The population concerned with this study is the project leaders on the one hand, especially for the project definition and monitoring phase, and the IT project managers from the project initialisation phase onwards.

\subsection{Sample}

A random sample of IT project managers was selected as the sample to identify the key factors of IT project failure. Data collection was done through interviews with the different entities that interact with the project, as well as direct observation in the field, in the case of a multinational IT services company.

This mix of qualitative and quantitative research allows us to understand the data in order to analyse it properly.

\subsection{Data collection}

The direct observation concerns IT projects that are under development, and the various interactions between project teams and managers, including end-users. Projects are observed in different phases of the IT project life cycle, in order to identify the constraints and difficulties encountered during each project phase.

Interviews are conducted with project managers, team members, the business, end-users and various project stakeholders, taking into consideration the project management method used.

The observation was made for a duration of two years (2018 and 2019), for 20 IT projects of different size, complexity and sector of activity, with more than 100 interviews with different types of interlocutors who interact directly or indirectly with the project.

\section{RESULTS}

Our direct observation in the field allowed us to identify in a somewhat detailed manner the problems encountered during the implementation of IT projects. Beyond direct observation and in order to better understand some of the identified factors, we opted for interviews with profiles of different levels of seniority and with the various members who interact in a direct or indirect manner for the implementation of this particular type of project.

Our criteria for analysing the success or failure of an IT project are as follows:

- quality

- budget

- planning

- business value

The first three criteria are always analysed for the investigations carried out by the different international groups, and we add to these criteria the business value of the project, because thousands of projects are carried out respecting these 3 criteria but which have never been useful for the company, and therefore cannot be considered as successful projects.

In this article, we summarize the most recurring factors that lead to the failure of IT projects in general. These factors are grouped by the phases that make up the IT project life cycle.

\section{Project definition:}

- Poor definition of the "why" of the project: companies focus on the "what" and "how" and forget the "why" that responds to a strategic need of the company.

- Poor knowledge of the different phases in a change: this implies no anticipation of users' reactions which must be managed in an efficient way.

- Lack of measurement criteria: this is one of the most recurring problems and is responsible for producing projects that never end. This, also implies the answer to the question "why", why the business wants the problem (the subject of the project) to be addressed. Without this answer, too many changes will take place during the implementation of the project, resulting in exploding budgets and schedules that 
keep changing over time.

\section{Project Planning \& Requirements}

- Underestimation of the planning: no method for planning IT projects, there are good practices, but not a well-defined repository that takes into account the different risks of project planning.

- Poor drafting of functional specifications: too many documents, but they are worthless because they do not correctly reflect the real need of the project.

\section{Development \& Testing}

- Poor definition of roles and responsibilities: which implies that some of the overarching objectives of the project are not properly addressed.

- No team spirit: because of communication plans that are not studied in advance.

- Weak risk management: companies pay particular attention to risks that may occur during the project definition phase, but once the project is launched, no strategy is put in place to measure and manage the risks that may arise during production.

- Rough testing and evaluation: the business tests the application in a different test environment from the production environment, and with access, rights that are broader than those are that will be available when the project goes into production. Therefore, everything works well during the testing phase, but they face new concerns when the project is launched in the production environment and with the rights defined for each role.

\section{Others :}

- Beyond the problems that can occur during each phase of the project, we find:

- Lack of visibility on the project: no strategy for updating tasks and planning is put in place, and the same goes for functional specifications that evolve over time without being documented (and therefore a solution that is difficult to maintain after its launch).

- Poor communication.

To summarize all of the above, Figure 2 presents the various issues identified and grouped by phase of the IT project life cycle:

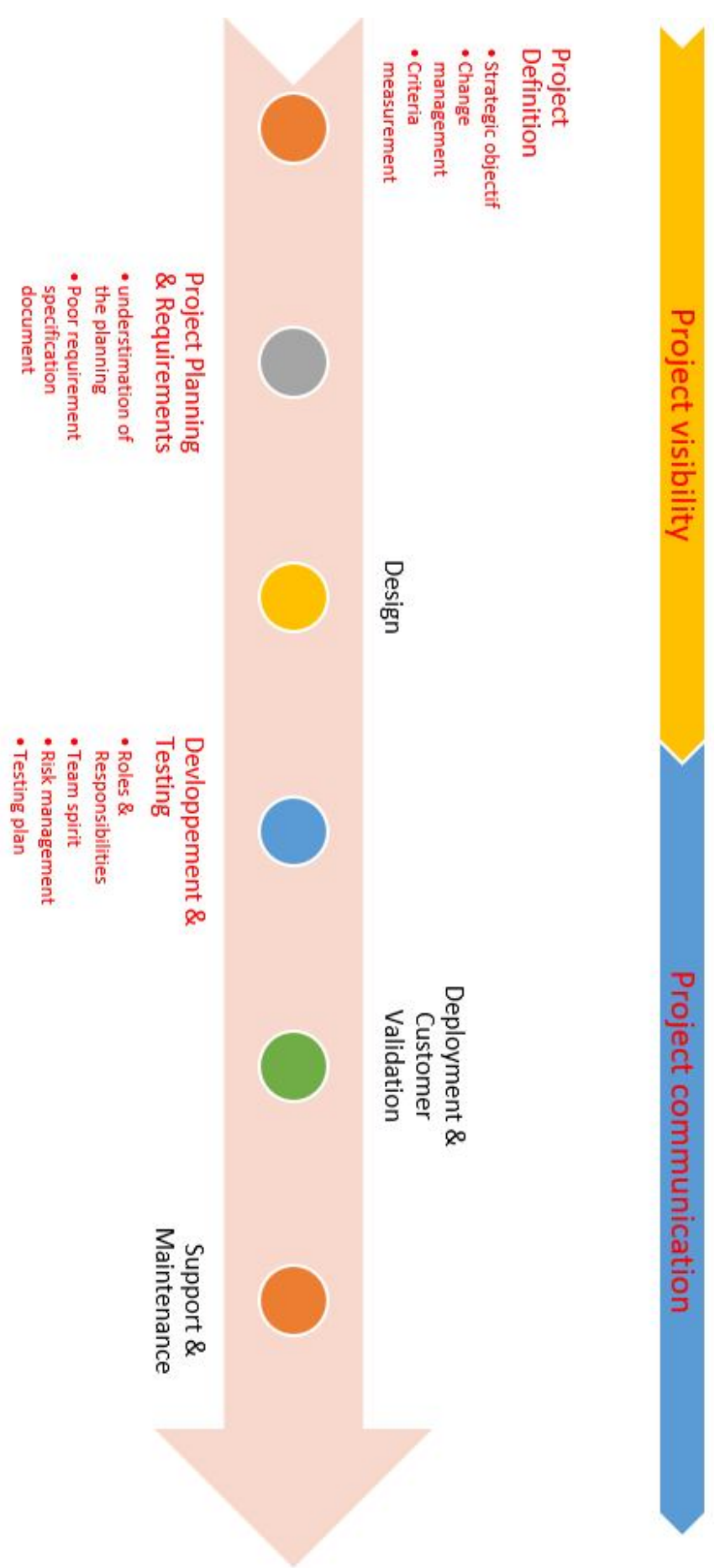

Figure 2: Common problems in the management of IT projects grouped by the project lifecycle steps

\section{DISCUSSION}

In this article, we propose a solution that allows you to define a precise framework for each phase of the life cycle of an IT project. Indeed, for each identified problem, we have defined several solutions based on feedback. Each solution has been tested on different projects in parallel of different size, 
complexity and characteristics in order to analyse its limits and improve it.

At the end of our tests, we kept only those solutions that had a very beneficial impact on the success of the project, and that proved to be effective on several projects (especially very high risk projects).

These solutions are defined as follows:

Project perimeter: This stage consists of defining the origin of the project, i.e. its priority objective, identifying its impact on the company (on users, contributors, indirect actors and above all the way to proceed). It also consists in identifying the rate of commitment (of the sponsor, users, contributors, as well as staff), this rate of impact in a direct way the duration of the project as well as its quality. Similarly, this step consists of the company to prepare itself methodically, we are talking mainly about the organizational method, and not the project management method. To finish with an analysis of the main objectives of the project using the SWOT (Strengths, Weaknesses, Opportunities, Threats) matrix, while defining the different means envisaged and a reformulation of the priority need of the project (in order to confirm the good understanding of the latter).

Project management method: two main methods of project management, the classical, linear methods, especially when the project scope is static and has no risk of change, and the agile, iterative methods, especially for projects where the need may change during the project implementation phase. The choice of method is based on team size, project complexity, the rate of change and evolving needs, and other project characteristics. This framework provides managers with a matrix that has as input the characteristics of the project and as output the most recommended method. In future studies, a method integrating the machine learning for the definition of the management method is to be considered.

Project organization: This step consists of defining the control mode and identifying a complete list of constraints that can occur during any stage of the project (legal, operational, etc.). Similarly, it consists in defining dependencies and interdependencies, identifying the actors, local, and project tools. Then, the definition of the macro planning according to a well-defined model to end with a risk assessment with their bypass plans.

Software requirement specification: also called the requirement specification document, and that's the equivalent of user stories in agile environments. In fact, this step consists of defining the functional perimeter of the project (functional specifications or user stories).

Project team: Having a competent technical team is essential for the success of the project. On the other hand, having a competent team that does not have a basic understanding of the project management method to be used, and without all members having a common vision of the model to be followed, is a factor that leads to the project's failure. This is in fact a risk to be anticipated from this early step.

Production planning: production planning is not limited to the realisation of a schedule, but in fact to the assignment of a team, the definition of a project committee according to the size of the project and its sensitivity. It is not only a question of planning the functional tasks, but a complete planning that includes a communication plan, a quality plan, a functional and non-functional task plan. A matrix that takes into consideration these different plans and the team responsible for the project must be considered, with a definition of the roles of the team members to avoid ambiguities when setting up the project. During this phase, it is necessary to identify the type of project management KPIs (EVPM, production quality or perceived quality KPIs), the latter must be mastered by the project manager, because using a KPI without knowing how to read it and understand the meaning of the indicators is also a factor in the failure of an IT project. Then, as a final step in this phase, the project must be divided into batches; each batch represents a set of functionalities, which must be classified by business value, by level of importance and then the level of urgency, and finally the planning of the latter, taking into consideration the estimates of the different functionalities. These estimates, must be made by the team that will handle the tasks.

Design: this phase consists of carrying out the design of the future system, a technical, functional and graphic design. One should not neglect the graphic design which limits the risks of functional and technical misunderstanding. An image is too meaningful than a text that can have several interpretations.

Development \& Testing: throughout the technical production, and the different types of tests and functional acceptance that represent a basis for validating development, it is necessary to take into consideration the management of iterations, the team (which may be self-organising). It is also necessary to know how to manage and organize the different project meetings, and the different types of meetings. Throughout this stage, it is necessary to pilot the project, i.e. the piloting by the indicators, and the application of Genchi Genbutsu, with a management of drifts, conflicts, and especially with a focus on the priority objectives of the project and an effective communication.

Deployment \& Customer validation: the deployment of the project has been a step already planned during the project definition phase, including the risks that may occur during this critical stage of the project. It is the last production step of the project to make it operational for the end users. A deployment requires a change management strategy that must be planned from the start of the project, because a project can be successful from a quality, duration and budget point of view, but a big failure for the company if it is not used by the end users and if it does not meet the priority objective of the project. During this phase, the project must be closed in 
operational and human terms. Indeed, the proposed framework requires these two stages to get off to a good start and prepare the ground for the final stage, which is the maintenance of the project.

To summarize the different stages of the proposed framework, we group them by phases of an IT project life cycle:

- Project definition:

oProject perimeter;

- project impact

- commitment

- workbench

- priority objectives (SWOT matrix)

- means envisaged

- reformulation of priority objectives

oProject management method;

- traditional approach

- agile method

- Project planning \& requirements:

oProject organization;

- control mode

- project constraints

- interdependence and dependence

- definitions of actors project, tools and premises

- risk-based assessment

- macro planning

oProject team;

- roles definition

- mastery of the management method used

- cross functional

ofunctional requirements;

- functional requirements

- non-functional requirements oProduction planning;

- definition of project committees

- communications strategy

- quality plan

- Management KPIs

- project subdivision

- batch planning

- Design

otechnical design

ofunctional design

ographic design

- Development \& testing

- Deployment \& customer validation

- Maintenance \& support

Finally, below is a schematic that summarizes the steps in the proposed framework:

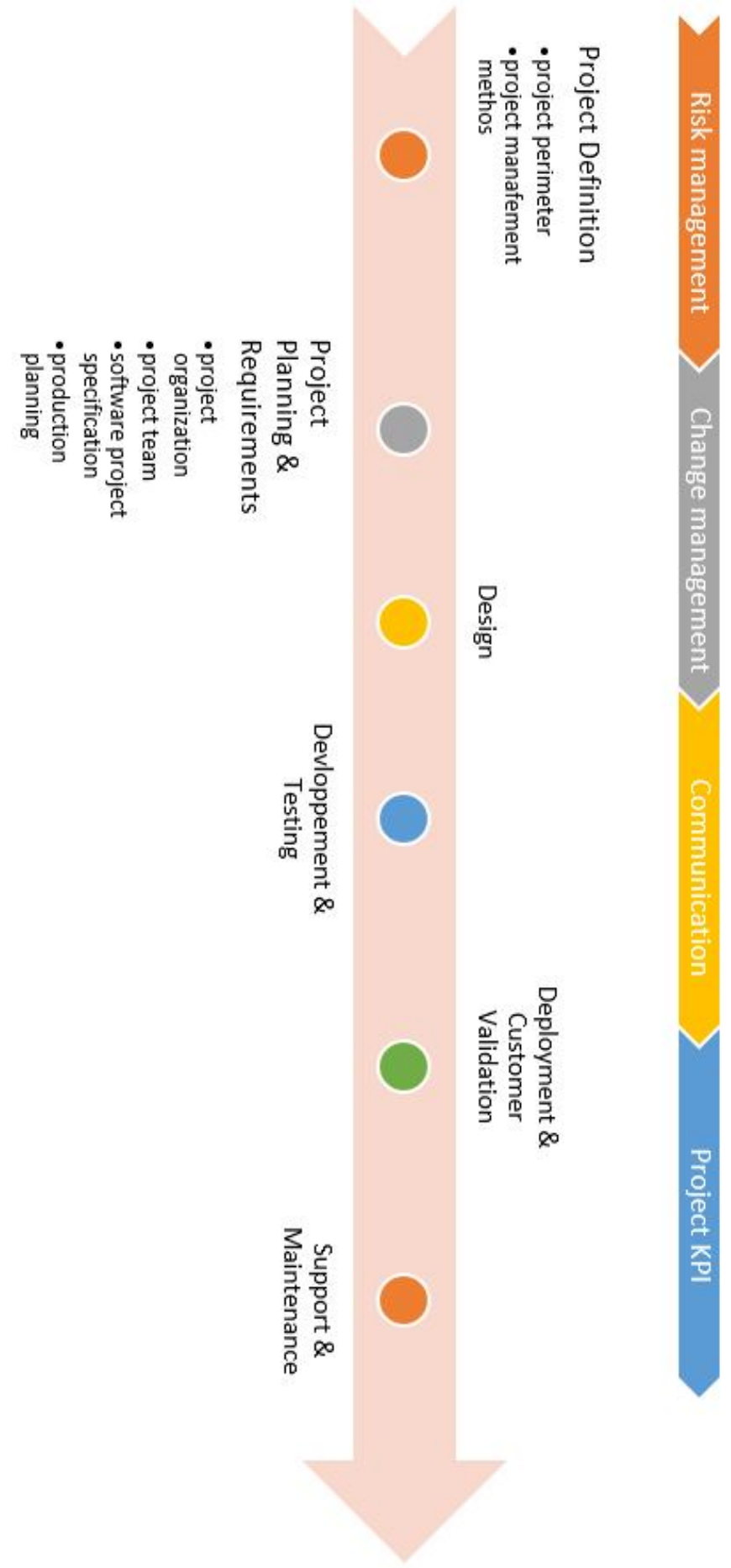

Figure 3: Proposal of a framework to define the different stages of the IT project life cycle

This framework has been tested through direct observation in the field on envigure projects. Similarly, improvement plans were brought to the latter during the 2-year solution-testing phase.

Strong points of the proposed solution following our tests:

- anticipation of project risks

- production planning control

- improvement in the quality of deliverables

- the business value of the project following its 
appropriation by the end users

- response to the project's priority objectives

- a single vision of the final objective of the project by the different team members

- compliance with the basic estimates which directly impacts the duration of the project

\section{Weaknesses :}

- the time spent on project management was very important compared to normal, we need to optimize this framework by automating a few elements

- add a phase for feedback so that it can be used for future projects

\section{CONCLUSION}

This article deals with the issue of IT project management in an era of digital transformation. This era is characterized by new constraints that have a direct impact on the management of IT projects. Indeed, this article proposes a framework to follow the progress of an IT project from its definition to its maintenance, by identifying the different methods and possible models of each phase and stage of the project. Thus, regardless of its complexity, its size, the size of its team and any other characteristics of the project.

The proposed solution has shown these fruits during its test phase, as it has participated in the improvement of the quality of the deliverables, better estimation of the projects by studying the different risks that impact the duration of the project, and therefore the planning. Thus, it allowed us to master the process and the different phases of the life cycle of an IT project, without the project manager getting lost in the search for existing models and the multitudes of solutions for each small step of the project.

Still, the proposed framework has limitations, which are reflected in the project manager's increased time spent on project implementation to identify the right method for each phase. However, further research can focus on improving this time, through the proposal of intelligent systems (integration of machine learning), in order to reduce the intervention of the project manager in making decisions on the method and model to be used for each phase.

\section{REFERENCES}

1. S. G. International, The CHAOS Report, 2003.

2. S. G. International, The CHAOS Report, 2013.

3. S. G. International, The CHAOS Report, 2015.

4. P. M. Institute, A Guide to the Project Management Body of Knowledge, The PMBOK(R) Guide - Sixth Edition, 2017.

5. R. Hassani et Y. E. B. E. Idrissi, Communication and software project management in the era of digital transformation, ICGDA, p. 22-26, 2018. https://doi.org/10.1145/3220228.3220254

6. R. Hassani et Y. E. B. E. Idrissi, Proposal of a framework and integration of artificial intelligence to succeed IT project planning, International Journal of Advanced Trends in Computer Science and Engineering, vol. Volume 8, n \% 16, pp. 3396 - 3404, 2019.

https://doi.org/10.30534/ijatcse/2019/114862019

7. R. Hassani et Y. E. B. E. Idrissi, Software Project Management in the era of digital transformation, NETYS 2017. Lecture Notes in Computer Science, vol. 10299, pp. 391-395, 2017. https://doi.org/10.1007/978-3-319-59647-1_28

8. L. $\mathrm{Xu}$ et $\mathrm{W}$. $\mathrm{Wu}$, Requirement management of IT, China Management In-formationization, pp. 80-82, 2010.

9. R. Hassani, Y. E. B. E. Idrissi et A. Abouabdellah, Digital project management in the era of digital transformation: Hybrid method, ICSIM, p. 98-103, 2018.

https://doi.org/10.1145/3178461.3178472

10. S. G. Internation, The CHAOS Reports, 2016. 